Supporting information for

\title{
Site-Specific Conjugation Strategy for Dual Antibody-Drug Conjugates Using Aerobic Formylglycine-Generating Enzymes
}

Mareile Boschanski ${ }^{\#, \dagger}$, Tobias Krüger ${ }^{\#, \ddagger}$, Lennard Karsten ${ }^{\S}$, Georg Falck ${ }^{\S}$, Sarfaraz Alam ${ }^{\dagger}$,

Marcus Gerlach ${ }^{\star}$, Benjamin Müller, Kristian M. Müller ${ }^{*}$, , Norbert Sewald ${ }^{*}$,

Thomas Dierks ${ }^{\dagger}$

$\dagger \quad$ Biochemistry, Faculty of Chemistry, Bielefeld University, Universitätsstraße 25, 33615 Bielefeld, Germany

* Organic and Bioorganic Chemistry, Faculty of Chemistry, Bielefeld University, Universitätsstraße 25, 33615 Bielefeld, Germany; E-mail: norbert.sewald@uni-bielefeld.de

§ Cellular and Molecular Biotechnology, Faculty of Technology, Bielefeld University, Universitätsstraße 25, 33615 Bielefeld, Germany; E-mail: kristian.mueller@uni-bielefeld.de

॥ Biofidus AG; Morgenbreede 1, 33615 Bielefeld, Germany; E-Mail: info@biofidus.de

\# Authors contributed equally

Dedicated to the memory of Thomas Dierks, our colleague, mentor, and friend.

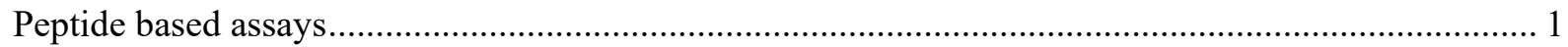

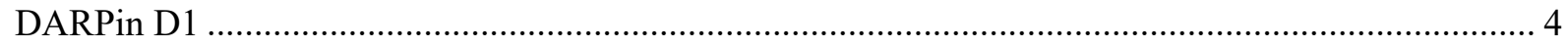

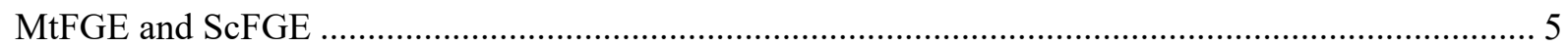

hFGE

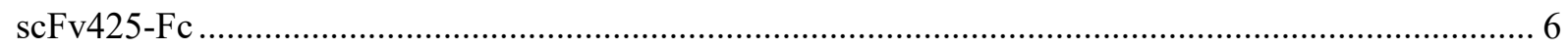

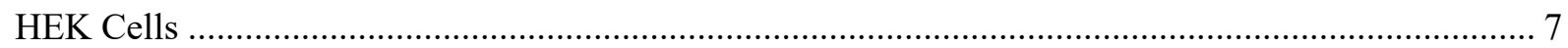

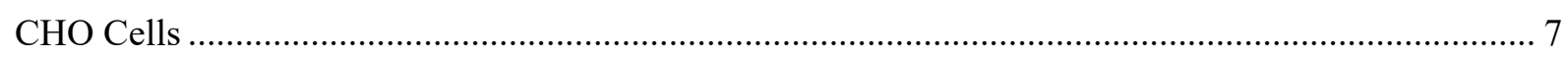

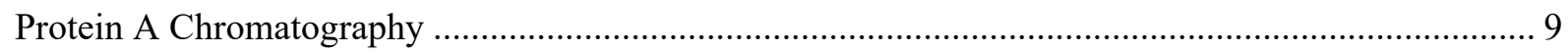

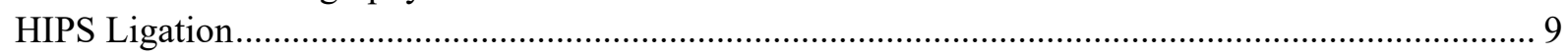

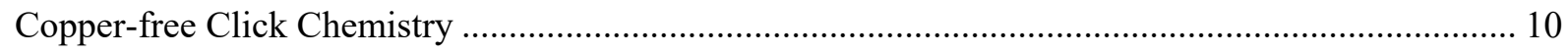

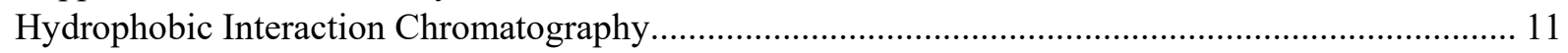

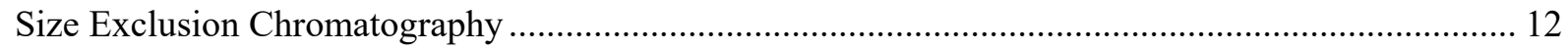

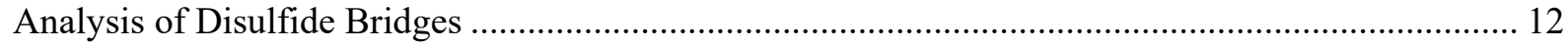

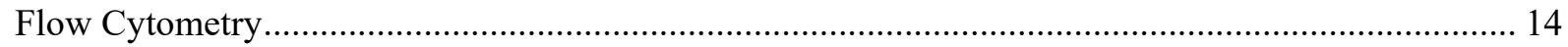

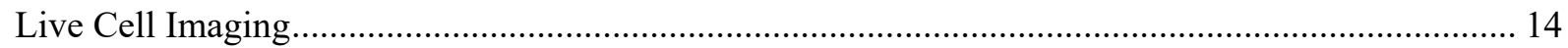

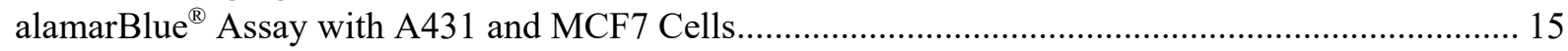

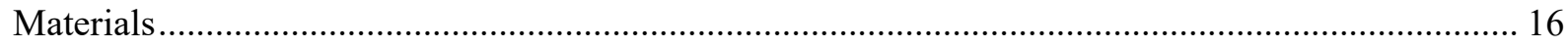

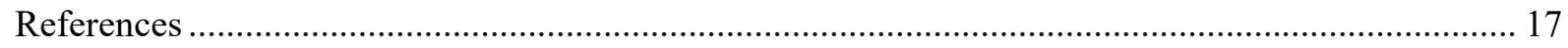




\section{Peptide based assays}

In vitro peptide conversion was done in bicine buffer $\mathrm{pH} 9,2-5 \mathrm{mM}$ DTT for $2 \mathrm{~h}$ at $37^{\circ} \mathrm{C}$. The enzyme-to-peptide ratio with and without the supplementation of equivalent concentrations of $\mathrm{CuSO}_{4}(12,5 \mu \mathrm{M})$ was 1:2. The reaction was stopped by using TFA and MALDI-ToF MS analysis were performed as described in Krüger et al., 2018. The peptide sequences of P1, P2 and P3 and their corresponding fragments in MS or MS/MS analysis at UltrafleXtreme MALDI-ToF/ToF (Bruker Daltonics) are listed in Table S1. The MALDI spectra of reference peptides or converted peptides by MtFGE, ScFGE or hFGE are given in Figures S1-S3. 
Table S1 Sequences and calculated $m / z$ values of peptides and fragments of peptides P1, P2, P3, DARPin D1 and

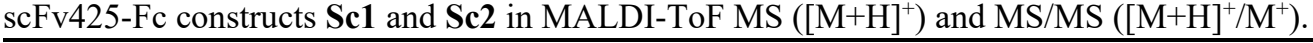

\begin{tabular}{|c|c|c|c|}
\hline Fragment & Sequence & $\begin{array}{c}m / z_{\text {calc }} \\
\left([\mathbf{M}+\mathbf{H}]^{+}\right)\end{array}$ & $\begin{array}{c}m / \text { zalc } \\
\left([\mathbf{M}+\mathbf{H}]^{+} / \mathbf{M}^{+}\right)\end{array}$ \\
\hline P1 & Ac-EQSCTAGRAAFITGQGLCTPSRAG-NH ${ }_{2}{ }^{1}$ & 2423.2 & \\
\hline P1a & Ac-EQS(FGly)TAGRAAFITGQGLCTPSRAG-NH 2 & 2405.2 & \\
\hline P1b & Ac-EQSCTAGRAAFITGQGL(FGly)TPSRAG-NH 2 & 2405.2 & \\
\hline P1c & Ac-EQS(FGly)TAGRAAFITGQGL(FGly)TPSRAG-NH 2 & 2387.2 & \\
\hline P1_y1 & H-TPSRAG-NH ${ }_{2}$ & & 587.3 \\
\hline P1_b1 & Ac-EQSCTAGRAAFITGQGL(FGly) & & 1818.8 \\
\hline P1 1 2 & H-TAGRAAFITGQGL(FGly)TPSRAG-NH 2 & & 1916.0 \\
\hline P1_b2 & Ac-EQS(FGly)TAGRAAFITGQGL(FGly) & & 1800.9 \\
\hline $\mathbf{P 1}$ & H-TAGRAAFITGQGL(FGly) & & 1329.7 \\
\hline P1_b3 & Ac-EQS(FGly) & & 489.1 \\
\hline $\mathbf{P 2}$ & Ac-GCTAGRGLCTPSR-NH 2 & 1319.6 & \\
\hline $\mathbf{P 2 a}$ & Ac-GCTAGRGL(FGly)TPSR-NH 2 & 1301.6 & \\
\hline $\mathbf{P 2 b}$ & Ac-G(FGly)TAGRGL(FGly)TPSR-NH ${ }_{2}$ & 1283.6 & \\
\hline P2c & Ac-G(FGly)TAGRGLCTPSR-NH ${ }_{2}$ & 1301.6 & \\
\hline P2 y & H-TPSR-NH 2 & & 459.3 \\
\hline P2_b1 & Ac-GCTAGRGL(FGly) & & 843.4 \\
\hline P2_b2 & Ac-G(FGly)TAGRGL(FGly) & & 825.4 \\
\hline $\mathbf{P 2} \_\mathbf{b} / \mathbf{y}$ & H-TAGRGL(FGly) & & 659.5 \\
\hline P3 & Ac-GLCTPSRAGPSGCTAGRAAFITGQ-NH 2 & 2320.1 & \\
\hline P3a & Ac-GL(FGly)TPSRAGPSGCTAGRAAFITGQ-NH 2 & 2302.1 & \\
\hline P3b & Ac-GL(FGly)TPSRAGPSG(FGly)TAGRAAFITGQ-NH 2 & 2284.1 & \\
\hline P3c & Ac-GLCTPSRAGPSG(FGly)TAGRAAFITGQ-NH 2 & 2302.1 & \\
\hline P3 $\mathbf{y}_{1}$ & H-TAGRAAFITGQ-NH ${ }_{2}$ & & 1091.6 \\
\hline P3_-1 1 & $\mathrm{O} \equiv \mathrm{C}-\mathrm{TAGRAAFITGQ- \textrm {NH } _ { 2 }}$ & & 1117.6 \\
\hline P3_y2 & H-TPSRAGPSGCTAGRAAFITGQ-NH ${ }_{2}$ & & 2005.0 \\
\hline P3_-1 2 & $\mathrm{O} \equiv \mathrm{C}-\mathrm{TPSRAGPSGCTAGRAAFITGQ- \textrm {NH } _ { 2 }}$ & & 2031,0 \\
\hline P3_y3 & H-TPSRAGPSG(FGly)TAGRAAFITGQ-NH 2 & & 1987.0 \\
\hline P3_x & $\mathrm{O} \equiv \mathrm{C}-\mathrm{TPSRAGPSG}$ (FGly)TAGRAAFITGQ-NH ${ }_{2}$ & & 2013,0 \\
\hline $\mathbf{P 3}+\mathbf{b} / \mathbf{y}$ & H-TPSRAGPSG(FGly) & & 896.4 \\
\hline P3_- $\mathbf{b}_{1}$ & Ac-GL(FGly)TPSRAGPSG(FGly) & & 1193.6 \\
\hline P3_b2 & Ac-GLCTPSRAGPSG(FGly) & & 1211.6 \\
\hline P3_b3 & Ac-GL(FGly) & & 297.1 \\
\hline P3_a1 & [Ac-GL(FGly)TPSRAGPSG(FGly)-(CO)+H'] & & 1167.6 \\
\hline P3_a2 & [Ac-GLCTPSRAGPSG(FGly)-(CO)+H $\left.{ }^{+}\right]$ & & 1185.6 \\
\hline D1 (tag) & ...-GGEQSCTAGRAAFITGQGLCTPSREASGADHHHHHH & & \\
\hline D1a & AAFITGQGLCTPSR & 1421.7 & \\
\hline D1b & AAFITGQGL(FGIy)TPSR & 1403.7 & \\
\hline D1c & TAFDISIDNGNEDLAEILQGGEQSCTAGR & 3024.4 & \\
\hline D1d & TAFDISIDNGNEDLAEILQGGEQS(FGly)TAGR & 3006.4 & \\
\hline Sc1 (tag) & ...-GGLCTPSRAALLTGRDIMHHHHHHTG & & \\
\hline Sc1a & DIGGLCTPSR & 1018.5 & \\
\hline Sc1b & DIGGL(FGly)TPSR & 1000.5 & \\
\hline Sc2 (tag) & ...-GGEQSCTAGRAAFITGQGLCTPSRTG & & \\
\hline Sc2a & AAFITGQGLCTPSR & 1421.7 & \\
\hline Sc2b & AAFITGQGL(FGIy)TPSR & 1403.7 & \\
\hline Sc2c & DGGEQSCTAGR & 1080.4 & \\
\hline Sc2d & DGGEQS(FGly)TAGR & 1064.2 & \\
\hline
\end{tabular}




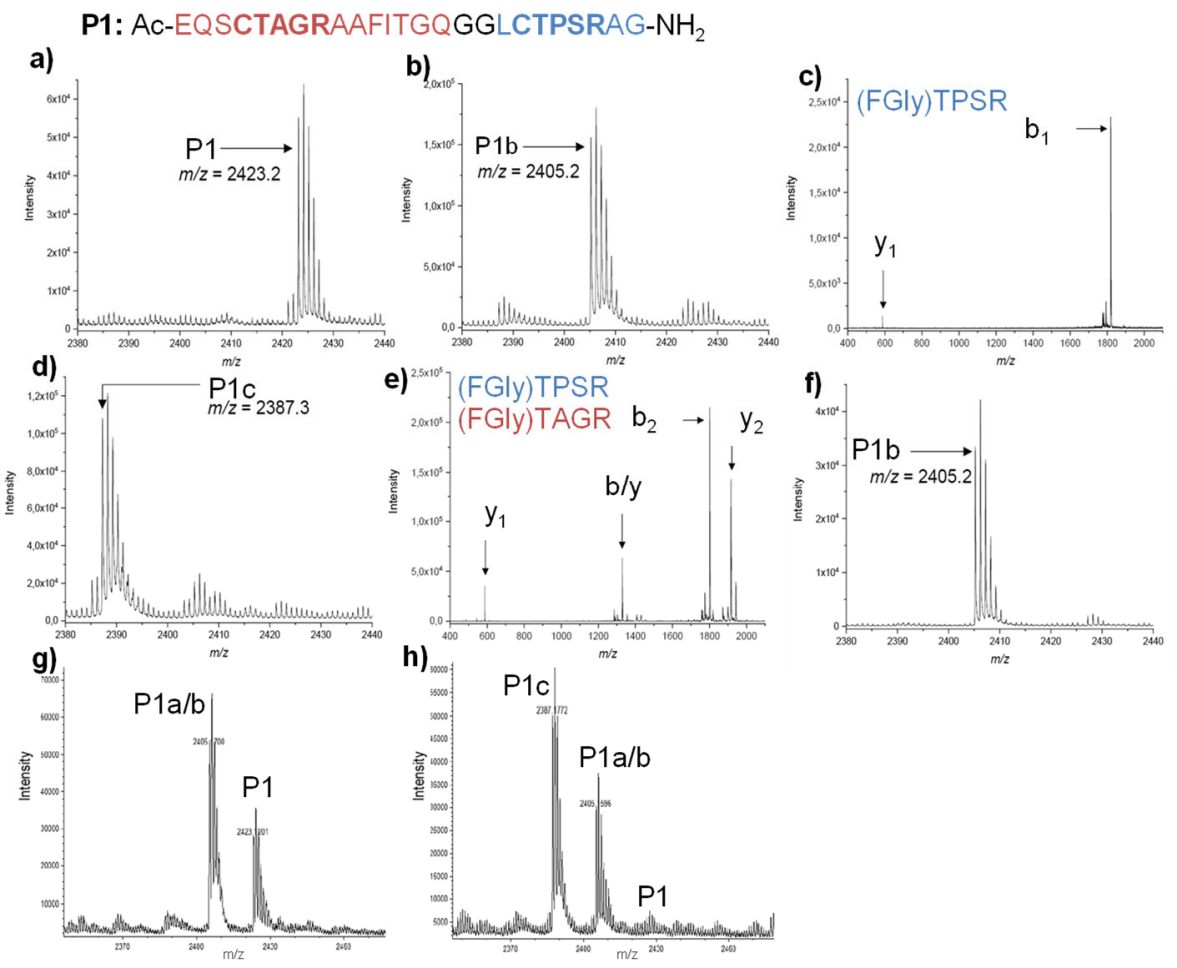

Figure S1 Conversion of peptide P1. a) Reference spectrum of P1. b) Conversion of P1 by MtFGE. c) MS/MSLIFT analysis of P1b from b) gives a distinct fragmentation of the (FGly)TPSR species. d) Conversion of P1 by MtFGE with one equivalent of $\mathrm{CuSO}_{4}$. e) MS/MS-LIFT analysis of P1c from d) gives evidence for the (FGly)TPSR and (FGly)TAGR species. f) Conversion of P1 by hFGE. g) Conversion of P1 with ScFGE. h) Conversion of $\mathbf{P 1}$ by $\mathrm{Cu}$-loaded $\mathrm{ScFGE}_{\text {rec}}$.
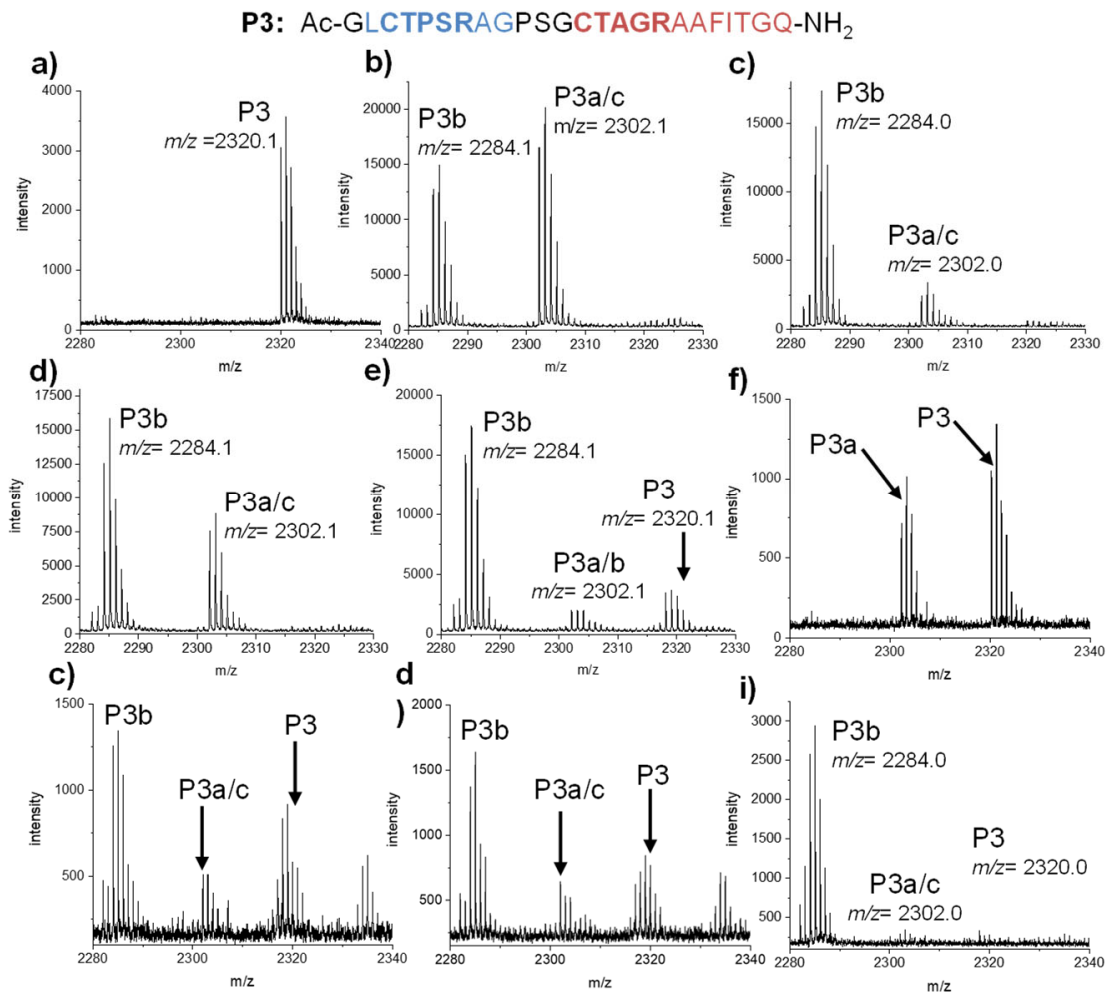

Figure S2 Conversion of peptide P3. a) Reference spectrum of P3. b) Conversion of P3 by ScFGE. c) Conversion of $\mathbf{P} 3$ by ScFGE with supplemented $\mathrm{CuSO}_{4}$. d) Conversion of $\mathbf{P} 3$ by $\mathrm{Cu}$-reconstituted $\mathrm{ScFGE}_{\text {rec. }}$ e) Conversion of $\mathbf{P 3}$ by $\mathrm{ScFGE}_{\text {rec }}$ with additional copper. f) Conversion of peptide $\mathbf{P} 3$ by MtFGE. g) Conversion of peptide $\mathbf{P 3}$ by MtFGE supplemented with $\mathrm{CuSO}_{4}$. h) Conversion of $\mathbf{P 3}$ by Cu-reconstituted MtFGE. i) Conversion of $\mathbf{P 3}$ by $\mathrm{MtFGE}_{\text {rec }}$ with additional $\mathrm{CuSO}_{4}$. 

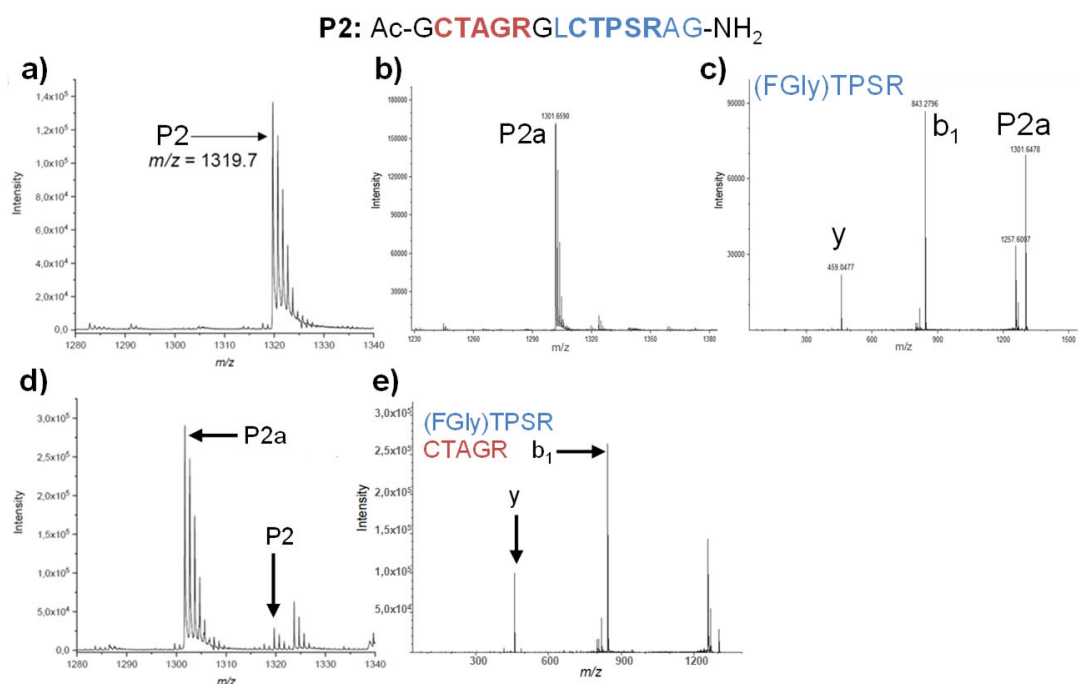

Figure S3 Conversion of peptide P2. a) Reference spectrum of $\mathbf{P 2}$. b) Conversion of $\mathbf{P 2}$ by hFGE. c) MS/MSLIFT analysis of peptide P2a from b) gives a distinct fragmentation of the (FGly)TPSR species. d) Conversion of P2 by MtFGE in presence of copper. e) MS/MS analysis of P2a reveals the presence of the (FGly)TPSR species but no conversion of the CTAGR motif.

\section{DARPin D1}

The DARPin D1 ${ }^{1,2}$ is made of the DARPin E01 and a C-terminal tag with two FGE recognition motifs and a hexa-histidine tag for standard HisTrap affinity purification: GGEQSCTAGRAAFITGQ-GLCTPSREASGADHHHHHH. The average mass is 20374.56 Da and the monoisotopic mass is 20362.03 Da. The CTAGR-containing fragment of tryptic digested D1 is: TAFDISIDNGNEDLAEILQGEQSCTAGR $\left(\mathrm{m} / \mathrm{z}_{\mathrm{calc}}=3024.39\right)$. In vivo protein conversion reactions were performed like mentioned above for peptide assays. The CTPSR-containing fragment of tryptic digested D1 is: AAFITGQGLCTPSR $\left(\mathrm{m} / \mathrm{z}_{\text {calc }}=1421.72\right)$. For further information see Table S1, Krüger et al. 2018, SI and Krüger et al. 2019, SI. MALDI spectra of converted D1 by MtFGE or ScFGE are given in Figure S4. 

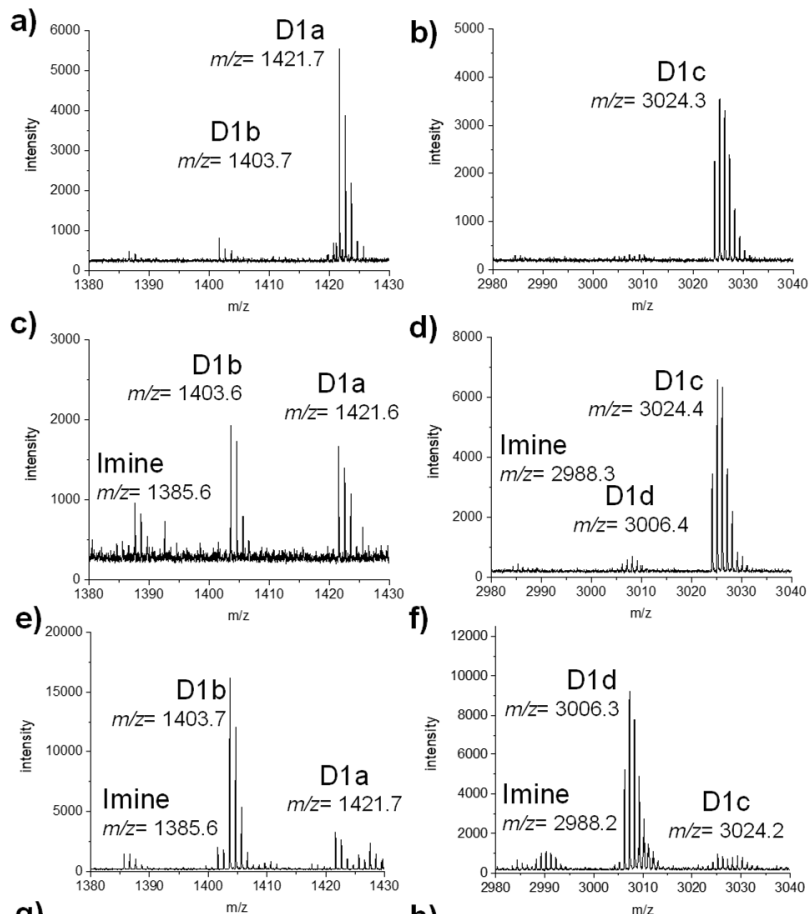

d) 8000 .
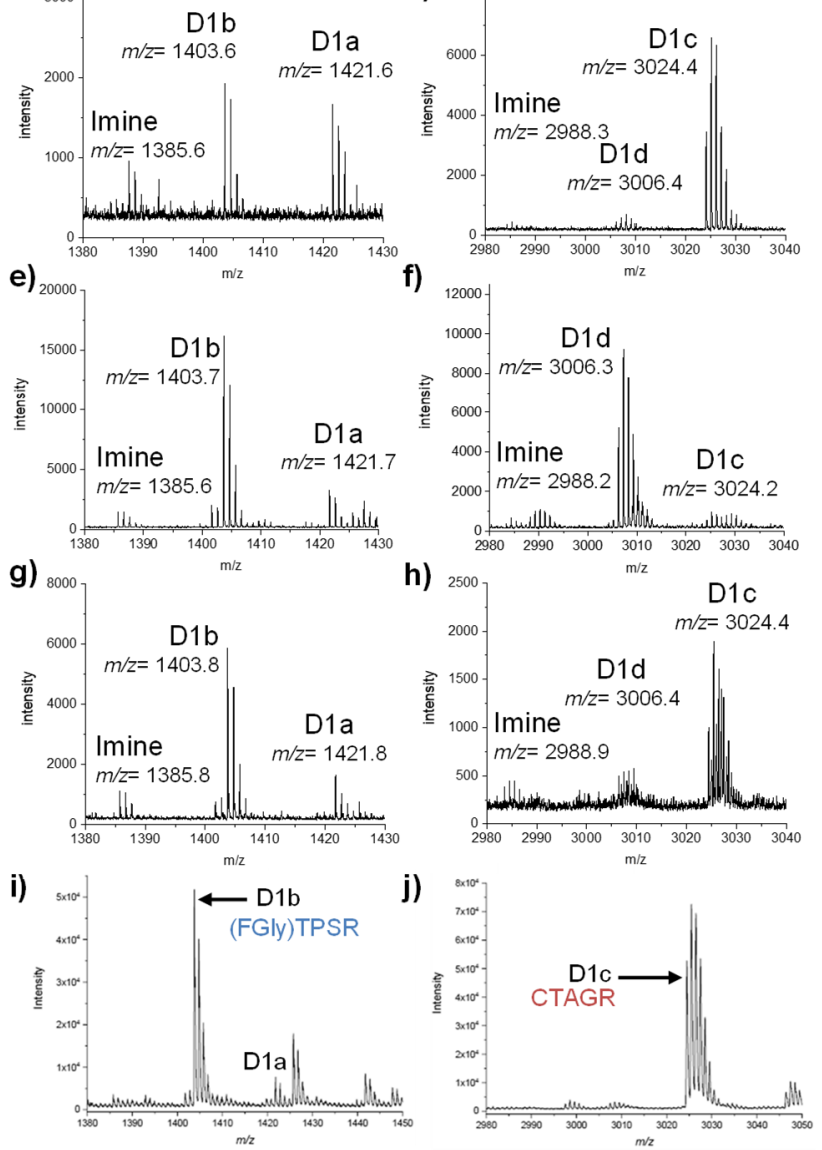

Figure S4 Conversion of DARPin D1. a) Reference spectrum of CTPSR fragment of D1. b) Reference spectrum of CTAGR fragment of D1. c) Conversion of D1 by MtFGE (CTPSR). d) Conversion of D1 by MtFGE (CTAGR). e) Conversion of D1 by MtFGE $\mathrm{rec}_{\text {rec }}(\mathrm{CTPSR})$. f) Conversion of $\mathbf{D} 1$ by $\mathrm{MtFGE}_{\mathrm{rec}}(\mathrm{CTAGR})$. g) Conversion of D1 by ScFGE (CTPSR). h) Conversion of D1 by ScFGE (CTAGR). i) Conversion of DARPin D1 to the single FGlycontaining D1b by hFGE holoenzyme. j) hFGE did not form an FGly within the CTAGR motif of D1.

\section{MtFGE and ScFGE}

The plasmid pET14b_MtbFGE was kindly obtained by D. Rabuka (Redwood Bioscience, Emeryville, USA) coding for the N-terminal hexa-histidine-tagged protein MtFGE with a molecular mass of $34.9 \mathrm{kDa}$. Protein expression in E. coli and purification by standard $\mathrm{Ni}^{2+}-$ affinity chromatography (HisTrap ${ }^{\circledR}$ HP) was performed as described in Krüger et al. 2018, SI. The plasmid pET14b_ScFGE is coding for the $37.2 \mathrm{kDa}$ protein ScFGE with a PreScission protease cleavage site between the N-terminal hexa-histidine tag and the protein. The tag of ScFGE is cleaved in an overnight reaction with PreScission protease (20:1) at $4{ }^{\circ} \mathrm{C}$. Reconstitution of MtFGE or ScFGE with copper is performed by the incubation of an enzyme- 
to-copper sulfate ration of 1:5 in $1 \mathrm{~mL}$ of $50 \mathrm{mM}$ Tris buffer supplemented with $50 \mathrm{mM} \mathrm{NaCl}$ at $\mathrm{pH} 7.5$ for $10 \mathrm{~min}$ at $25^{\circ} \mathrm{C}$ and constant shaking, followed by the addition of EDTA $(5 \mathrm{x} \mathrm{Cu}$ concentration) for $10 \mathrm{~min}$ at $25^{\circ} \mathrm{C}$. Buffer exchange was performed at a PD-10 desalting column, eluted in Tris buffer. For long-term storage of MtFGE $200 \mathrm{mM}$ arginine is added. 1.5-2 h incubation of a 1:2-ration of enzyme to substrate in bicine buffer $\mathrm{pH} 9.3$ containing 2-5 mM DTT leads to a conversion of recognition sequences in vitro.

\section{hFGE}

The gene of the human formylglycine-generating enzyme (hFGE) with a C-terminal RGSHHHHHH tag was cloned in the multiple cloning site of the pcDNA ${ }^{\mathrm{TM}} 5 / \mathrm{FRT}$ vector (Thermo/Invitrogen) by the restriction enzymes NheI and NotI, resulting in pcDNA5_hFGEWT-His. Additionally, the hFGE sequence with the mutations R69A and R72A (short RRA) was cloned analogously, resulting in the vector pcDNA5_hFGE-RRA-His. Out of each hFGEsequence two additional variants were made by PCR, substituting the C-terminal tag by ERretention signals KDEL or PGEL: pcDNA5_hFGE-WT-KDEL, pcDNA5_hFGE-RRA-KDEL, pcDNA5_hFGE-WT-PGEL and pcDNA5_hFGE-RRA-PGEL. The resulting genes of about $1.14 \mathrm{~kb}$ are coding for proteins of about $41 \mathrm{kDa}$ and were transiently expressed in CHO cells or used for the production of stable CHO cell lines. Purification of human FGE is performed by viral infection and protein expression in insect cell culture. For further information see Peng et al. 2015. The hFGE performs the FGly conversion in vitro in bicine buffer at $\mathrm{pH} 9.3$ in presence of 2-5 mM DTT at $25^{\circ} \mathrm{C}$ for up to $16 \mathrm{~h}$ or alternatively at $37^{\circ} \mathrm{C}$ for shorter time periods.

\section{ScFv425-Fc}

The gene of the single-chain antibody fragment scFv425 directed against the epidermal growth factor receptor (EGFR) and the gene for the human Fc of IgG1 were cloned in the multiple cloning site of the pcDNA5/FRT vector from Invitrogen by the restriction enzymes NheI and ApaI, resulting in the plasmid pcDNA5/FRT_Sp-RAGE_scFv425_Fc-IgG1_His6 (pZMB0687), coding for one monomer of the single-chain antibody Sc0 with the N-terminal signal peptide of the receptor for advanced glycosylation end products (RAGE) and a Cterminal His 6 tag. Via add-on PCR the following FGE recognition motifs were added:

Sc1 (pcDNA5/FRT_Sp-RAGE_scFv425_Fc-IgG1_FGEmot_His6, pZMB0148):

GGLCTPSRAALLTGRDIMHHHHHHTG.

Sc2 (pcDNA5/FRT_Sp-RAGE_scFv425_Fc-IgG1_mmAtsB-FGEmot2, pZMB0520):

GGEQSCTAGRAAFITGQGLCTPSRTG (no purification tag). 
The resulting protein Sc0 without aldehyde tag has a molecular mass of $\mathrm{M}_{\mathrm{w} \text {,calc }}=54179.4 \mathrm{Da}$. Sc1 has an average mass of 55862.3 Da and a monoisotopic mass of 55827.0 Da. The CTPSRcarrying fragment of tryptic digested Sc1 is DIGGLCTPSR $\left(\mathrm{m} / \mathrm{z}_{\mathrm{calc}}=1018.50\right)$. The processed protein Sc2 has an average mass of 55462.8 Da and a monoisotopic mass of 55427.8 Da. Tryptic digest of Sc2 results in the CTPSR-carrying fragment AAFITGQGLCTPSR $\left(\mathrm{m} / \mathrm{z}_{\mathrm{calc}}=1421.72\right)$ and the CTAGR-carrying fragment DGGEQSCTAGR $\left(\mathrm{m} / \mathrm{z}_{\mathrm{calc}}=1080.44\right)$.

\section{HEK-293 cell culture and antibody expression}

The cell line HEK FreeStyle ${ }^{\mathrm{TM}}$ 293-F (Invitrogen/Thermo) was cultivated in suspension culture for antibody expression. The medium HEK TF (Xell) was supplemented with $8 \mathrm{mM} \mathrm{L}$ Glutamine. Transient expression was performed in $250 \mathrm{~mL}$ shake flasks with orbital shaking at $185 \mathrm{rpm}$ and $5 \mathrm{~cm}$ amplitude at $37^{\circ} \mathrm{C}$ and $5 \% \mathrm{CO}_{2}$ with initial $60 \mathrm{~mL}$ cell suspension. Prior to transfection, 293-F cells were washed with PBS. Transient transfection of $3.0 \times 10^{6}$ cells $/ \mathrm{mL}$ was carried out with PEI MAX 40K (Polysciences) by mixing $2 \mu \mathrm{g}$ DNA (pZMB0148, pZMB0520 or pZMB0687) with $8 \mu \mathrm{g}$ PEI (1:4 DNA-PEI ratio) in $250 \mu \mathrm{L}$ HEK TF for the transfection of $1 \mathrm{~mL}$ cells. $4 \mathrm{~h}$ post-transfection $1 \mathrm{~mL}$ medium was added per $1 \mathrm{~mL}$ suspension. The cultivation of cells lasted until the viability of cells dropped below $50 \%$. Cells were harvested at $2000 \times \mathrm{g}$ for $5 \mathrm{~min}$, the cell culture supernatant was sterile filtered and applied to subsequent Protein A purification.

\section{Stable FGE expressing CHO cell line}

The cell line Flp-In-CHO (Invitrogen/Thermo) was used to create stable FGE expressing cells. The genes to be stably expressed were cloned into the pcDNA5/FRT vector (see above) and cotransfected in adherent Flp-In-CHOs by PEI transfection with the pOG44 vector for recombinase expression. Cells with successful recombination event were selected by hygromycine resistance, zeocine sensitivity and X-Gal white/blue coloring following the vendor's manual. Selected clones were tested for hFGE gene by sequencing and hFGE expression by western blotting of lysates with specific anti-hFGE or anti-RGSHis antibodies (Qiagen).

\section{Antibody expression in the CHO-FGE cell line}

Transient expression of single-chain antibody scF425-Fc was performed in $125 \mathrm{~mL}$ shake flasks with orbital shaking at $185 \mathrm{rpm}$ and $5 \mathrm{~cm}$ amplitude at $37{ }^{\circ} \mathrm{C}$ and $5 \% \mathrm{CO}_{2}$ in $\mathrm{CHO}-\mathrm{TF}$ medium (Xell) with initial $30 \mathrm{~mL}$ cell suspension. Prior to transfection, CHO cells were washed with PBS. Transient transfection of $3.0 \times 10^{6}$ cells $/ \mathrm{mL}$ was carried out with PEI MAX 40K (Polysciences) by mixing $2 \mu \mathrm{g}$ DNA (pZMB0148 or pZMB0520) with $8 \mu \mathrm{g}$ PEI (1:4 DNA-PEI 
ratio) in $125 \mu \mathrm{L}$ CHO-TF (Xell) for the transfection of $1 \mathrm{~mL}$ cell suspension. $4 \mathrm{~h}$ posttransfection $2 \mathrm{~mL}$ TC-42 medium (Xell) was added per $1 \mathrm{~mL}$ culture. The cultivation of cells lasted until the viability of cells dropped below $50 \%$. Cells were harvested at $2000 \times \mathrm{g}$ for $5 \mathrm{~min}$, the cell culture supernatant was sterile filtered and applied to subsequent protein A purification. Cysteine conversion to formylglycine was determined by MALDI-ToF MS (Figure S5).

a)
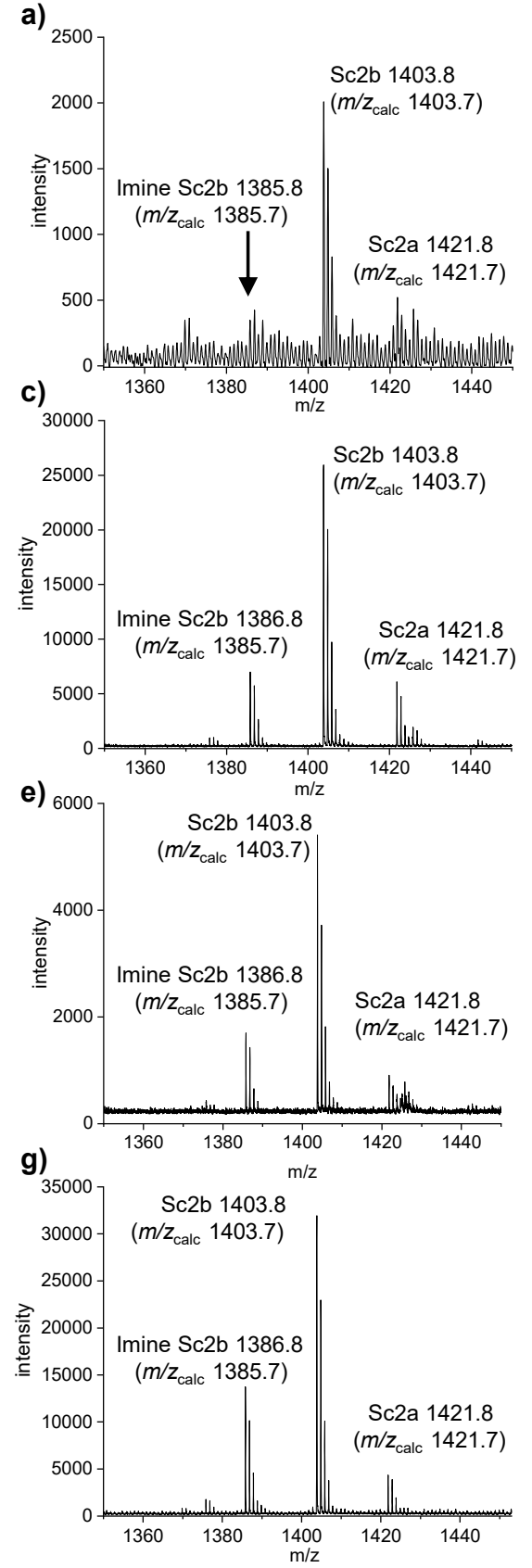

b)

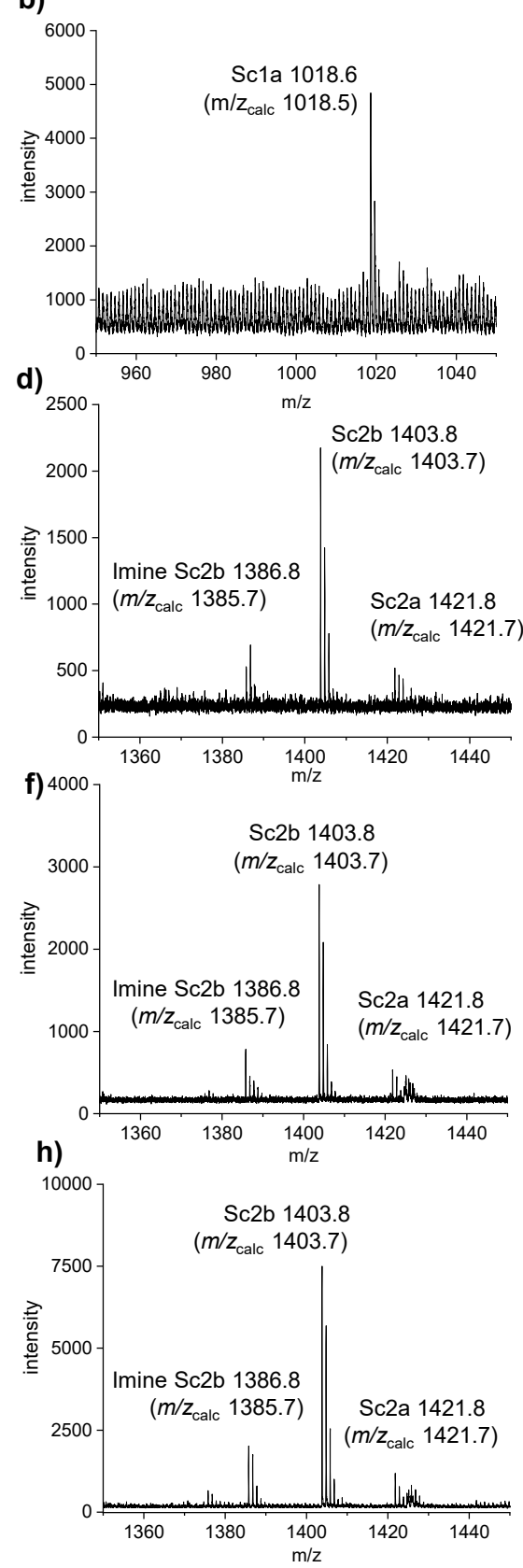

Figure S5 MALDI-ToF MS spectra for the determination of in vivo FGly rates found in the CTPSR motif of scFv425-Fc constructs after coexpression with hFGE variants in suspension culture. The (FGly)TAGR species was not found. a) Sc2 transient expressed in HEK cells in the presence of endogenous hFGE. b) Sc1 transient expressed in $\mathrm{CHO}$ cells. c) $\mathbf{S c 2}$ coexpressed in CHO cells stably expressing hFGE-WT-His. d) Sc2 coexpressed in $\mathrm{CHO}$ cells stably expressing hFGE-RRA-His. e) Sc2 coexpressed in CHO cells stably expressing hFGE-WTKDEL. f) Sc2 coexpressed in CHO cells stably expressing hFGE-RRA-KDEL. g) Sc2 coexpressed in CHO cells stably expressing hFGE-WT-PGEL. h) Sc2 coexpressed in CHO cells stably expressing hFGE-RRA-PGEL. 


\section{Antibody purification by Protein A chromatography}

Antibody purification was performed using Protein A chromatography with the $1 \mathrm{~mL}$ column HiTrap $^{\text {TM }}$ Protein A HP (GE Life Sciences/cytiva) on Äkta Explorer or Äkta Start (GE Life Sciences) chromatogprahy system, according to the manufacturer's manual: binding buffer: 50 $\mathrm{mM}$ Tris, $150 \mathrm{mM} \mathrm{NaCl}$, $\mathrm{pH}$ 8.0; elution buffer: $50 \mathrm{mM} \mathrm{Na}_{3} \mathrm{PO}_{4}, 50 \mathrm{mM}$ citrate, $150 \mathrm{mM} \mathrm{NaCl}$, $\mathrm{pH} 3.0$; neutralization buffer: $0.5 \mathrm{M}$ Tris, $150 \mathrm{mM} \mathrm{NaCl}, \mathrm{pH} 8.5$. The cell supernatant was centrifuged, sterile filtered and loaded on the equilibrated column at $1 \mathrm{~mL} / \mathrm{min}$. The column was washed with 15 column volumes $(\mathrm{CV})$ binding buffer. Elution was performed with $10 \mathrm{CV}$ elution buffer, collected in $0.5 \mathrm{~mL}$ fractions and neutralized with $0.1 \mathrm{~mL}$ of neutralization buffer. Chromatogrpahy was monitored by measuring absorption at $280 \mathrm{~nm}$ and conductivity (Figure S6). Purified protein was stored in an arginine-containing buffer at $-80{ }^{\circ} \mathrm{C}$ prior use.
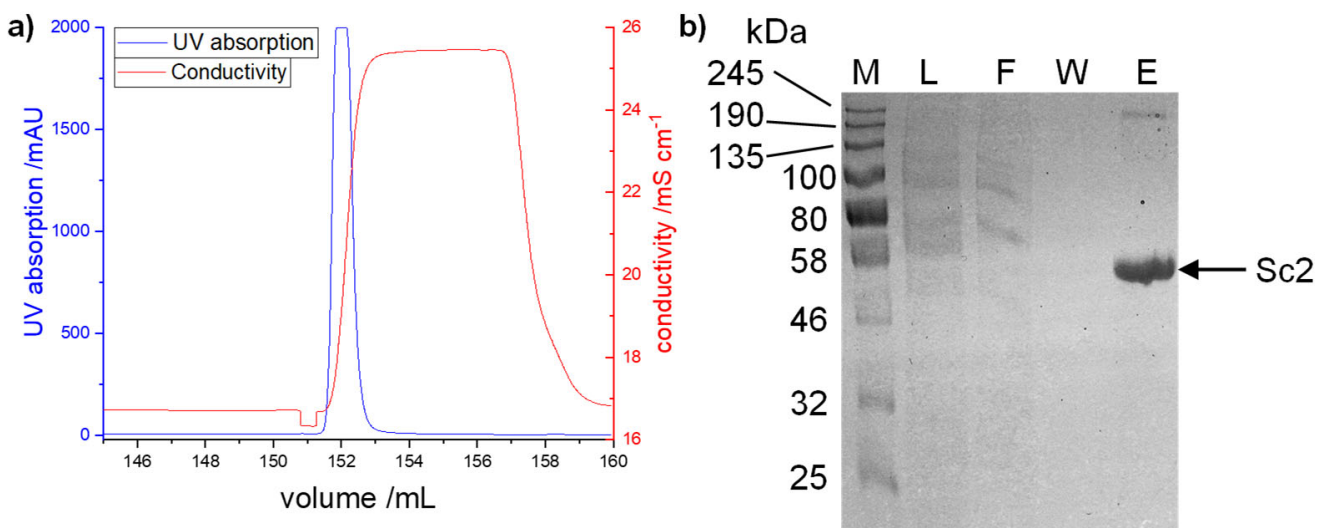

Figure S6 Protein A affinity chromatography of Sc2. a) The cell culture supernatant was loaded on the $1 \mathrm{~mL}$ column, washed with binding buffer and eluted with $10 \mathrm{~mL}$ elution buffer. The magnified elution chromatogram shows the UV absorption ( $280 \mathrm{~nm}$; blue) and conductivity at the switch to elution buffer. The buffer change is monitored by increasing conductivity (red). Purified protein was collected in $1 \mathrm{~mL}$ fractions and neutralized with $100 \mu \mathrm{L}$ neutralization buffer. b) Reductive SDS-gel (12\%) of the cell culture supernatant (L), the flow-through (F), the wash fraction (W) and $10 \mu \mathrm{g}$ of eluted protein Sc2 (E). M: Molecular mass marker.

\section{HIPS Ligation}

Hydrazino-iso-Pictet-Spengler ligation is performed in acidic $\mathrm{pH}$ at 6.0 for an overnight reaction (at least $15 \mathrm{~h}$ ) at $22{ }^{\circ} \mathrm{C}$ and constant shaking. Conjugation reactions should not contain any arginine or glycine. Therefore, buffer of protein solutions was exchanged by centrifugal concentrators (Vivaspin ${ }^{\circledR}$ Turbo 15). The aldehyde bearing protein was incubated with the reagent HIPS-azide, HIPS-CF or HIPS-PEG (1 M stock solution) in a ratio of up to 1:10. The reagents were synthesized as described in the Supporting Information of Krüger et al., 2018 and Janson et al., 2020. The reaction mixture was centrifuged due to precipitates and then either analyzed via hydrophobic interaction chromatography or SDS-PAGE or the product was reconcentrated by affinity chromatography and applied to click chemistry. 


\section{Copper-free Click Chemistry}

The strain-promoted azide-alkyne cycloaddition (SPAAC) between an azide and the DBCOPEG or DBCO-PEG-VC-PAB-MMAE (5 mM stock solution in DMSO) was performed at $\mathrm{pH}$ 9.0 for at least $2 \mathrm{~h}$ and $22^{\circ} \mathrm{C}$ at constant shaking. Circa 1.1 equivalents of DBCO-reagents were used. The product was either used for further enzymatic conversions or purified by HIC and analyzed by ESI MS, MALDI-ToF MS or in SDS-gels.

The analysis of single CF- or MMAE-conjugated antibody constructs of Sc1 and Sc2 was done by SDS-PAGE (see Figure S7) MALDI-ToF MS or HIC (see Figure S8).

a)

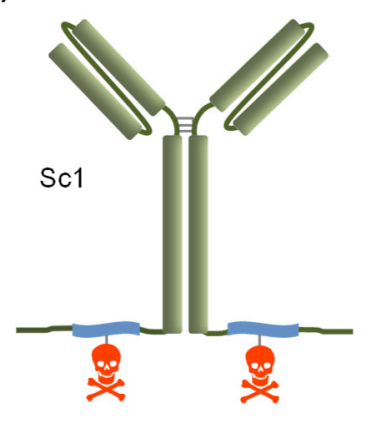

b)

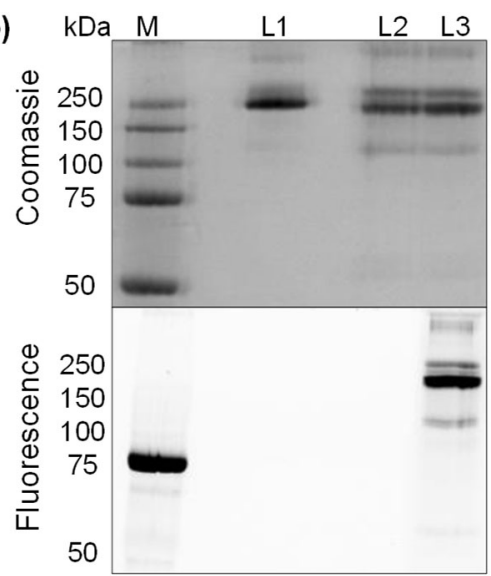

Figure S7 Conjugation of single tagged Sc1. a) Scheme of a Sc1 ADC with one payload per chain. b) Coomassiestained (upper section) and fluorescence image (lower section) of a non-reductive SDS-gel (12.5\%) with the oligomeric single-chain antibody Sc1 and the carboxyfluorescein-conjugated Sc1-CF. L1: Sc1 with CTPSR tag. L2: Sc1 incubated with hFGE and DTT. L3: Sc1 converted by hFGE in the presence of DTT and conjugated with HIPS-CF. M: Molecular mass marker. 


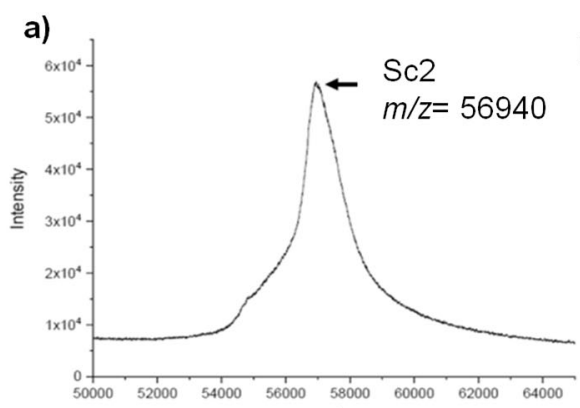

c)

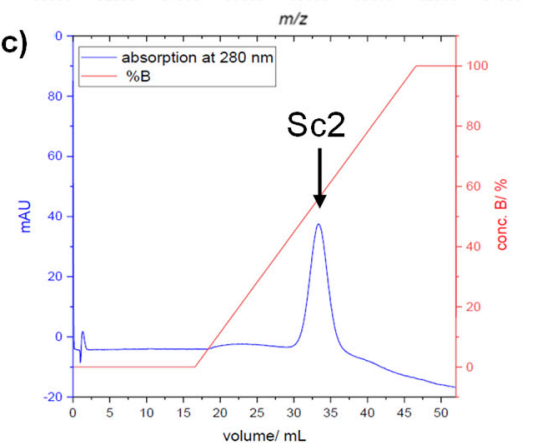

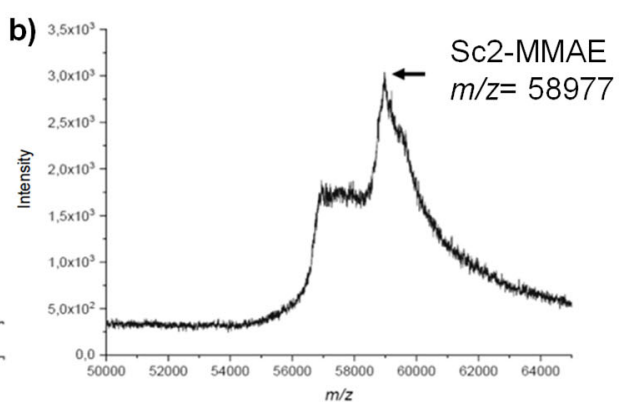

d)
$+++$

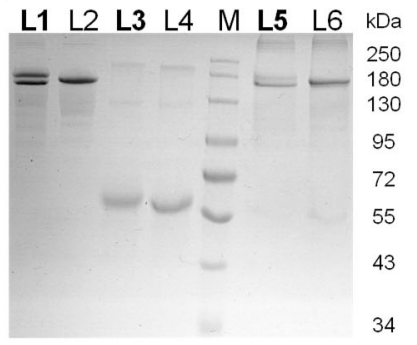

Figure S8 Analysis of Sc2 and Sc2-conjugates. a) Whole protein MALDI-ToF MS analysis of the unconjugated Sc2 construct with CTPSR-CTAGR tag. b) MALDI spectrum of Sc2-MMAE. c) HIC elution chromatogram of the unconjugated Sc2. Absorption was measured at $280 \mathrm{~nm}$. d) Coomassie-stained SDS-gel (8.5\%) of dimeric Sc2 (bold) and tag-free scFv425-Fc under non-reducing conditions (L1 and L2). To show redimerization both species were incubated with $2.5 \mathrm{mM}$ DTT for $1 \mathrm{~h}$ at $37^{\circ} \mathrm{C}$ and $800 \mathrm{rpm}$ (L3-L6) to create conditions used in FGE conversion reactions. Analog to the protein recovery steps in conjugation reactions, the DTT removal was performed via a buffer exchange by Protein A sepharose (L5-L6). Bound protein was washed with binding buffer and elution fractions were neutralized with neutralization buffer and incubated for $20 \mathrm{~h}$ at $22^{\circ} \mathrm{C}$ and $800 \mathrm{rpm}$ (conjugation conditions). All samples were mixed with Laemmli buffer and heat denatured for $5 \mathrm{~min}$ at $95^{\circ} \mathrm{C}$ prior SDS-PAGE. M: Molecular mass marker.

\section{Hydrophobic Interaction Chromatography}

Hydrophobic interaction chromatography (HIC) was done to isolate the conjugation products. Therefore, a HiTrap ${ }^{\mathrm{TM}}$ Phenyl HP $1 \mathrm{~mL}$ column was used on Äkta Explorer pump system (at $4{ }^{\circ} \mathrm{C}$ ) according to the manufacturer's manual. Binding buffer A: $1 \mathrm{M}\left(\mathrm{NH}_{4}\right)_{2} \mathrm{SO}_{4}, \mathrm{pH} 7.0$. Elution buffer B: $18.75 \mathrm{mM} \mathrm{NaH}_{2} \mathrm{PO}_{4}, 25 \%$ isopropanol, $\mathrm{pH} 7.0$. The reaction mixture was centrifuged, sterile filtered, mixed with binding buffer (1:1) and loaded on the equilibrated column at $1 \mathrm{~mL} / \mathrm{min}$. The column was washed with $10 \mathrm{CV}$ binding buffer. Elution was performed by a linear gradient of $30 \mathrm{CV}$ elution buffer at $1 \mathrm{~mL} / \mathrm{min}$ while collecting $0.5 \mathrm{~mL}$ fractions. Absorption was measured at $280 \mathrm{~nm}$ (Figure S9). 


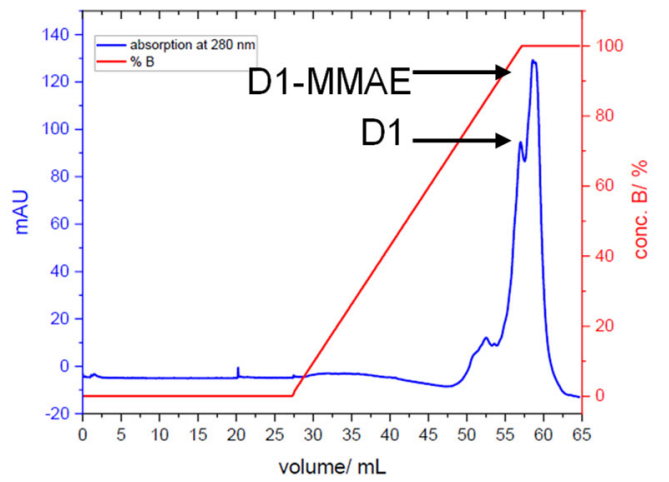

Figure S9 HIC chromatogram of the DARPin D1 with CTAGR-CTPSR motif. The conjugation with MMAE took place at the (FGly)TPSR motif. The reaction mixture was loaded on HIC column, eluted in a linear gradient of elution buffer B and collected in $0.5 \mathrm{~mL}$ fractions. Absorption at $280 \mathrm{~nm}$ shows an overlapping peak profile.

\section{Size Exclusion Chromatography}

Size exclusion chromatography (SEC) of native proteins was performed under phosphate buffer pH 7.5 at the Äkta Ettan system with a $500 \mu \mathrm{L}$ sample loop and the Superdex 200 Increase 10/300 GL column with a column volume of $25 \mathrm{~mL}$. The measurement of a standard protein mix out of Dextran Blue (2000 kDa), Ferritin (444 kDa), Bovine Serum Albumin (67 kDa), Ovalbumin $(45 \mathrm{kDa})$, Cytochrome c $(12.5 \mathrm{kDa})$ and Aprotinin $(6.5 \mathrm{kDa})$ and the molecular mass determent of proteins and conjugates was performed at $0.5 \mathrm{~mL} \cdot \mathrm{min}^{-1}, \mathrm{RT}$. Absorption was measured at $280 \mathrm{~nm}$.

\section{Analysis of Disulfide Bridges}

For the analysis of the two different states of the non-reduced $\mathbf{S c 2}$ construct a comparison to untagged scFv425-Fc (Sc0) was done by non-reductive SDS-PAGE (Figure S10 a) and gelbands, as well as proteins in solution, were prepared for mass spectrometry. Gel bands were destained with $50 \%$ methanol and washed with water before dehydration in $100 \%$ acetonitrile. Rehydration was done with $100 \mathrm{mM}$ Tris $\mathrm{pH} 6.5$ containing $100 \mathrm{mM}$ iodacetamide (IAA) for $20 \mathrm{~min}$ at $37^{\circ} \mathrm{C}$ to fixate free thiols. The solution was exchanged to Tris buffer, the residual Coomassie stain was extracted by acetonitrile incubation and the gel slices were dried via speedvac for $2 \mathrm{~min}$. For digestion, the slices were incubated for $30 \mathrm{~min}$ at $4{ }^{\circ} \mathrm{C}$ in digestion solution (25 $\mu \mathrm{L}$ of $100 \mathrm{mM}$ Tris $\mathrm{pH} 6.5,2 \mathrm{mM} \mathrm{CaCl}, 2 \mu \mathrm{g}$ Trypsin/LysC mixture) and afterwards overnight at $37^{\circ} \mathrm{C}$ in additional digestion solution. Peptides were extracted with $50 \%$ acetonitrile and $0.5 \%$ formic acid and again with $75 \%$ acetonitrile and $1 \%$ formic acid followed by speed-vac treatment. The dried peptides were resuspended in $1 \%$ acetonitrile and $1 \%$ formic acid prior mass spectrometry. Proteins in solution were buffered in Tris $\mathrm{pH}$ 6.5, digested in digestion solution and prepared in $1 \%$ acetonitrile and $1 \%$ formic acid analogously. 
The samples were separated on a HPLC-system (Agilent 1100) using a reversed phase column (AdvanceBio Peptide Map 2.1 x 100 mm, $2.7 \mu \mathrm{m}$, Agilent). Eluents were 0.1\% formic acid in water and $0.1 \%$ formic acid in acetonitrile. The mass spectrometric analysis was performed with a Compact QTOF mass spectrometer (Bruker Daltonics). The recorded LC-ESI MS and MS/MS spectra were processed and annotated using DataAnalysis (Bruker Daltonics) and searched for disulfide linked peptides against the theoretical sequence of the analyzed protein using MeroX (University of Halle-Wittenberg). A database containing the disulfide linked peptides of the protein was generated. For both samples, the disulfide linked peptides indicating characteristic and non-characteristic disulfide linkages were identified by their exact mass and retention time and quantified by their mass spectrometric signal intensity. While all analyzed disulfides within the scFv425-Fc construct were concurring, differences between $\mathbf{S c 0}$ and $\mathbf{S c 2}$ were only observed in the region of the C-terminal aldehyde tag where the cysteines $\mathrm{C} 487$ and C501 (Figure S10 b and c) are either performing inter- or intramolecular disulfides, giving evidence for a disulfide shuffling event that is most likely to be the reason for two conformational states of $\mathrm{Sc} 2$ resulting in a double-band.

a) IAA:

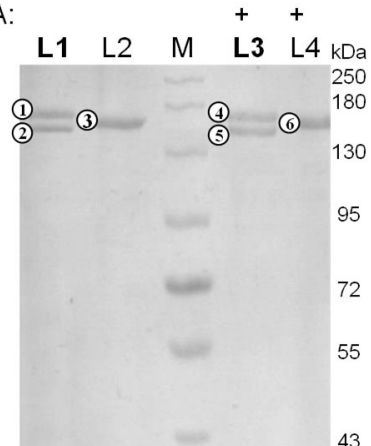

c)

$\begin{array}{lrrrrr} & \text { Sc2 } & \text { Sc2 (1) } & \text { Sc2 (2) } & \text { Sc2 (4) } & \text { Sc2 (5) } \\ \text { C487-C487 } & 37.4 \% & 1.6 \% & 55.5 \% & 2.6 \% & 53.8 \% \\ \text { C487-C501 } & 62.6 \% & 98.4 \% & 44.5 \% & 97.4 \% & 46.2 \% \\ \text { C501-C487 } & 59.8 \% & 94.5 \% & 26.0 \% & 93.3 \% & 24.8 \% \\ \text { C501-C501 } & 40.2 \% & 5.5 \% & 74.0 \% & 6.1 \% & 75.2 \%\end{array}$

b)

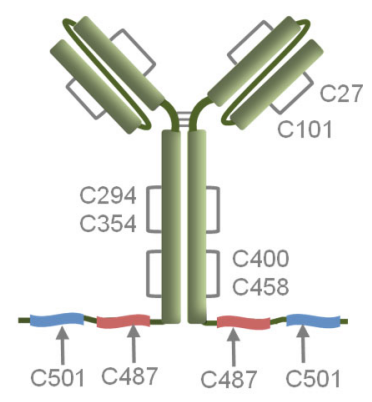

Figure S10 Disulfide analysis. a) Coomassie-stained, non-reductive SDS-gel (8.5\%) of dimeric Sc2 (bold) and tag-free scFv425-Fc (Sc0) without (L1-L2) and with treatment of $50 \mathrm{mM}$ Iodacetamide (IAA) (L3-L4). All samples were mixed with Laemmli buffer and heat denatured for $5 \mathrm{~min}$ at $95{ }^{\circ} \mathrm{C}$ prior SDS-PAGE. The marked protein bands (1)-(6) were analyzed by mass spectrometry. M: Molecular mass marker. b) Scheme of the doubletagged scFv425-Fc with highlighted cysteines. c) Table of determined disulfide content by mass spectrometry. Samples of the Sc2 and the untagged Sc0 were investigated after in-solution or in-gel digest from a), (1)-(6). The varying disulfide contents of the C-terminal cysteines of Sc2 (in solution and bands (1), (2), (4), (5)) are given in percentages. 


\section{Flow Cytometry}

Adherent A431 cells $\left(2.0 \times 10^{5}\right.$ cells $\left./ \mathrm{mL}\right)$ and adherent MCF7 cells $\left(1.5 \times 10^{5}\right.$ cells $\left./ \mathrm{mL}\right)$ were cultivated in RPMI medium in 6-well plates for one day and washed with PBS twice. Cells were incubated with Sc2-CF dimer (0-100 nM) in $1 \mathrm{~mL}$ RPMI medium for $5 \mathrm{~min}$ at $37{ }^{\circ} \mathrm{C}$ and washed again with PBS twice. For detachment cells were treated with $400 \mu \mathrm{L}$ Accutase (SigmaAldrich/Merck) solution for $10 \mathrm{~min}$ at $37^{\circ} \mathrm{C}$. MCF7 cells were measured directly while the faster growing A431 cells were diluted in PBS prior flow cytometry with an S3e Cell Sorter (BioRad) and detection in the 525/30 nm channel upon excitation at $488 \mathrm{~nm}$. Analogous experiments with D1-CF were published in Krüger et al. 2018, SI.

\section{Live Cell Imaging}

The A431 and MCF7 cells were cultivated in 8-well Lab-Tek ${ }^{\mathrm{TM}}$ chamber slides (Nunc/Thermo) with $0.8 \mathrm{~cm}^{2}$ surface area for one day $\left(2.0-2.5 \cdot 10^{4}\right.$ cells $\left./ \mathrm{mL}\right)$ and washed with phenol redlacking RPMI medium. The incubation with $100 \mathrm{nM} \mathrm{CF-tagged} \mathrm{Sc2} \mathrm{dimer} \mathrm{lasted} 10$ min at 37 ${ }^{\circ} \mathrm{C}$, followed by two additional washing steps with PBS. LysoTracker Blue DND-22 (Thermo) was used in a final concentration of $150 \mathrm{nM}$ for $10-15 \mathrm{~min}$ at $37^{\circ} \mathrm{C}$, followed by two washing steps. Pictures were taken with a Zeiss LSM 780 confocal fluorescence microscope at indicated time points, starting from the protein incubation (Figure S11). Colocalization was analyzed by ImageJ software. Analog experiments with D1-CF were published in Krüger et al. 2018, SI. 


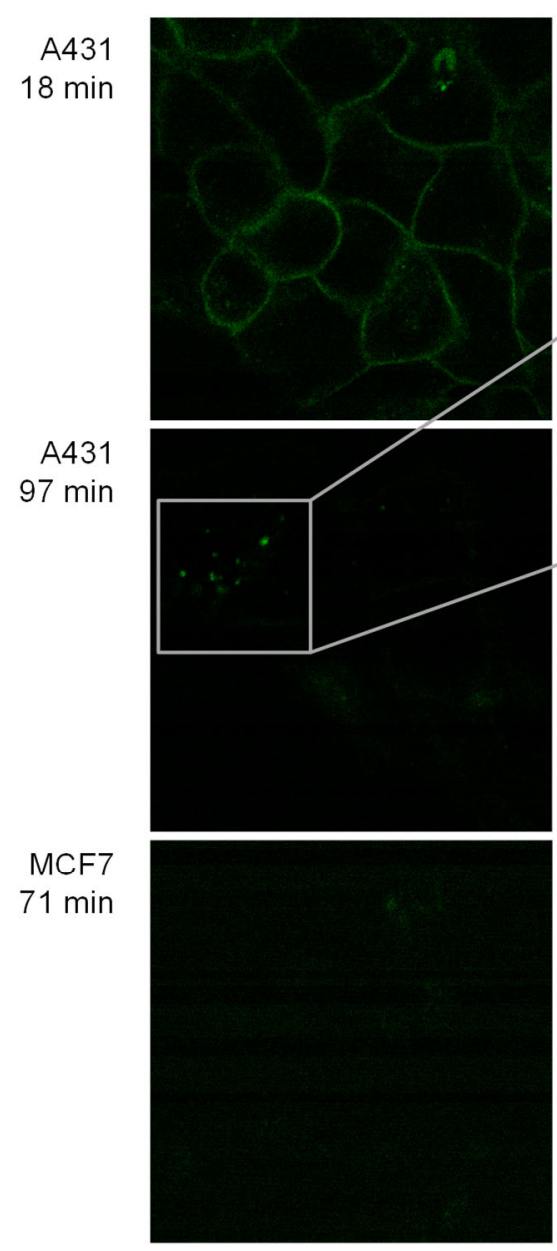

green:Sc2-CF
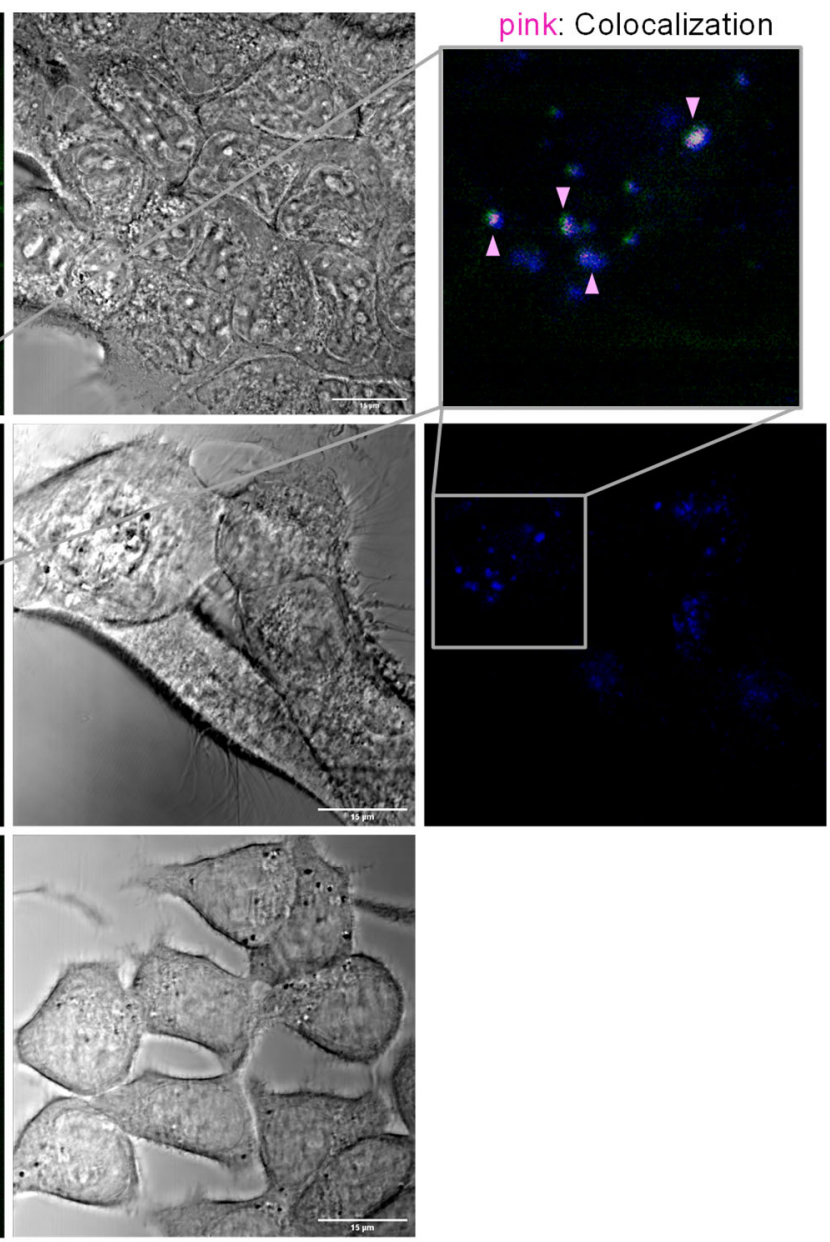

DIA blue: LysoTracker

Figure S11 Life Cell Imaging (LCI) of Sc2-MMAE-CF dual conjugate. Receptor binding on plasma membrane and internalization of dual tagged single-chain antibody scFv-425-Fc (green) was detected on cells with high (A431) EGFR level whereas no comparable results were received on negative control cells (MCF7). In the image magnification inset of A431 cells after $97 \mathrm{~min}$, colocalization of Sc2-MMAE-CF with lysosomes stained with LysoTracker (blue) is pseudo-colored in light pink and highlighted by arrows.

\section{alamarBlue assay with A431 and MCF7 cells}

The cytotoxic activity of scFv425-Fc-ADCs with MMAE was tested in a fluorescence-based cell assay. Adherent A431 and MCF7 cells were cultivated in RPMI medium with glutamine $(5 \%)$ and fetal bovine serum $(10 \%)$ at $37{ }^{\circ} \mathrm{C}$ and $5 \% \mathrm{CO}_{2}$. 96-well plates were seeded with a cell density of $1.0 \times 10^{5}$ cells $/ \mathrm{mL}$. Cells were treated either with DBCO-PEG-VC-PAB-MMAE or Sc2-MMAE for $72 \mathrm{~h}$ at $37^{\circ} \mathrm{C}$ in a concentration range of $0.01 \mathrm{nM}-5 \mathrm{mM}$ diluted in RPMI in at least triplicates. Untreated cells, cells treated with Sc2, and cells with DMSO-containing buffers in appropriate dilutions were included as controls. After $72 \mathrm{~h}$, cells were washed with PBS. A final concentration of $0.02 \%$ alamarBlue reagent dissolved in RPMI medium $(200 \mu \mathrm{L})$ was used for incubation at $37^{\circ} \mathrm{C}$ for 2 to $4 \mathrm{~h}$. Control wells were filled with reagent (no cells) or reduced reagent. The fluorescence was measured hourly at $590 \mathrm{~nm}$ in a Tecan Spark Multimode Microplate Reader at $590 \mathrm{~nm}$ with four measurements per well. An increase in 
fluorescence compared to untreated cells is achieved by the metabolic reduction of the resazurin dye and serves as a reporter for cell viability. The logarithmic dependencies of the relative metabolic activities to the concentration of toxins or ADCs and the resulting $\mathrm{IC}_{50}$ values were analyzed with GraphPad Prism software. The $\mathrm{IC}_{50}$ value gives the concentration of a test substance which results in a $50 \%$ reduction of cell viability.

\section{Materials}

Table S2 Materials and equipment list with exact product name and manufacturer.

\begin{tabular}{|c|c|}
\hline Product & Manufacturer \\
\hline HisTrap $^{\mathrm{TM}} \mathrm{HP}$ & GE Healthcare, Marlborough, MA, USA \\
\hline Hiload $^{\mathrm{TM}}$ 16/600 Superdex 200 & GE Healthcare, Marlborough, MA, USA \\
\hline MonoQ $^{\mathrm{TM}} \mathbf{5 / 5 0}$ GL & GE Healthcare, Marlborough, MA, USA \\
\hline HiTrap $^{\mathrm{TM}}$ Phenyl HP & GE Healthcare, Marlborough, MA, USA \\
\hline HiTrap $^{\mathrm{TM}}$ Protein A HP & GE Healthcare, Marlborough, MA, USA \\
\hline AdvanceBio Peptide Map & Agilent Technologies, Santa Clara, CA, USA \\
\hline Äkta Explorer & GE Healthcare, Marlborough, MA, USA \\
\hline Äkta Ettan & GE Healthcare, Marlborough, MA, USA \\
\hline Äkta Start & GE Healthcare, Marlborough, MA, USA \\
\hline Agilent 1100 HPLC-System & Agilent Technologies, Santa Clara, CA, USA \\
\hline PD-10 Desalting Column & GE Healthcare, Marlborough, MA, USA \\
\hline Superdex 200 Increase 10/300 GL & GE Healthcare, Marlborough, MA, USA \\
\hline CICCA matrix & Sigma-Aldrich, St. Louis, MO, USA \\
\hline UltrafleXtreme $^{\mathrm{TM}}$ MALDI-ToF/ToF & Bruker Daltonics, Bremen, Germany \\
\hline Compact QTOF mass spectrometer & Bruker Daltonics, Bremen, Germany \\
\hline Vivaspin ${ }^{\circledR}$ Turbo 15 Ultrafiltration Unit & Sartorius, Göttingen, Germany \\
\hline DBCO-PEG-VC-PAB-MMAE & MedChemExpress, Sollentuna, Sweden \\
\hline Flp-In ${ }^{\mathrm{TM}}-\mathrm{CHO}$ & Invitrogen, Carlsbad, CA, USA \\
\hline HEK FreeStyle & Thermo Fisher Scientific, Waltham, MA, USA \\
\hline High Five $^{\mathrm{TM}}$ cells (BTI-Tn-5B1-4) & Thermo Fisher Scientific, Waltham, MA, USA \\
\hline Sf9 cells (ATCC CRL-1711) & Thermo Fisher Scientific, Waltham, MA, USA \\
\hline A431 & ATCC CRL-1555 \\
\hline MCF7 & ATCC HTB-22 \\
\hline RPMI medium & Thermo Fisher Scientific, Waltham, MA, USA \\
\hline Flp-In ${ }^{\mathrm{TM}}$ system & Invitrogen, Carlsbad, CA, USA \\
\hline pcDBA5 ${ }^{\mathrm{TM}} / \mathrm{FRT}$ vector & Invitrogen, Carlsbad, CA, USA \\
\hline PEI MAX 40K & Polysciences, Warrington, PA, USA \\
\hline TC-42 & Xell AG, Bielefeld, Germany \\
\hline CHO-TF & Xell AG, Bielefeld, Germany \\
\hline HEK-TF & Xell AG, Bielefeld, Germany \\
\hline Accutase $^{\circledR}$ solution & Sigma-Aldrich, St. Louis, MO, USA \\
\hline S3E Cell Sorter & Bio-Rad Laboratories, Hercules, CA, USA \\
\hline LSM 780 & Zeiss, Oberkochen, Germany \\
\hline LysoTracker ${ }^{\circledR}$ Blue DND-22 & Thermo Fisher Scientific, Waltham, MA, USA \\
\hline Nunc $^{\mathrm{TM}}$ Lab-Tek ${ }^{\mathrm{TM}}$ Chamber Slide ${ }^{\mathrm{TM}}$ & Thermo Fisher Scientific, Waltham, MA, USA \\
\hline alamarBlue $^{\circledR}$ reagent & Thermo Fisher Scientific, Waltham, MA, USA \\
\hline Spark ${ }^{\circledR}$ Multimode Microplate Reader & Tecan Group, Männedorf, Switzerland \\
\hline GraphPad Prism & GraphPad Software, San Diego, CA, USA \\
\hline
\end{tabular}




\section{References}

1. Krüger T., Weiland S., Falck G., Gerlach M., Boschanski M., Alam S., Müller K. M., Dierks T., Sewald N. (2018) Two-fold Bioorthogonal Derivatization by Different Formylglycine-Generating Enzymes. Angew. Chem. Int. Ed. 57, 7245-7249.

2. Krüger T., Weiland S., Boschanski M., Sinha P. K., Falck G., Müller K. M., Dierks T., Sewald N. (2019) Conversion of Serine-Type Aldehyde Tags by the Radical SAM Protein AtsB from Methanosarcina mazei. ChemBioChem 20, 2074-2078.

3. Peng J., Alam S., Radhakrishnan K., Mariappan M., Rudolph M. G., May C., Dierks T., Von Figure K., Schmidt B. (2015) Eukaryotic formylglycine-generating enzyme catalyses a monooxygenase type of reaction. FEBS J. 282, 3262-3274.

4. Janson N., Krüger T., Karsten L., Boschanski M., Dierks T., Müller K. M., Sewald N. (2020) Bifunctional Reagents for Formylglycine Conjugation: Pitfalls and Breakthroughs. ChemBioChem. 21, 3580-3593. 